\title{
In-situ Conservation of Commiphorawightii: an Endangered Medicinal Shrub through Integrated Participatory Approach in the Nagarparkar Hills of Tharparkar, Pakistan
}

\author{
AzizAhmed $^{1}$, TanveerArif ${ }^{2}$, MaharAmanullah ${ }^{3}$, Humaira wasila $^{8}$, Imran Ahmad $^{7, *}$ Bharumal Amrani $^{2}$, \\ Saeed Akhtar Abro ${ }^{4}$, Siraj Ahmed Channa ${ }^{5}$, Zahid Hussain Jalbani ${ }^{6}$ \\ ${ }^{1}$ Aalborg University, Department of Development and Planning, Aalborg, Denmark \\ ${ }^{2}$ Society for Conservation and Protection of Environment (SCOPE), Pakistan \\ ${ }^{3}$ Centre for Environmental Sciences, University of Sindh, Jamshoro 76080, Pakistan \\ ${ }^{4}$ Institute of Plant Sciences, University of Sindh, Jamshoro 76080, Pakistan \\ ${ }^{5}$ Department of Plant Breeding \& Genetics, SAU Tandojam\&0060, Pakistan \\ ${ }^{6}$ Strengthening Participatory Organization, 30-A, Main Nazimunddin Road, F-10/4, Islamabad, Pakistan \\ ${ }^{7}$ College of Horticulture, NorthwestA \& F University, Yangling, Shaanxi, 712100, P R. China \\ ${ }^{8}$ College of Food science and EngineeringNorthwest A \& F University, Yangling, Shaanxi, 712100, P R China \\ *Corresponding author: imran73aup@yahoo.com
}

Copyright (C) 2013 Horizon Research Publishing All rights reserved.

\begin{abstract}
Participatory oriented actions were taken in district Tharparkar (South-eastern Pakistan) to combat desertification effects through conserving Commiphora wightii, an endangered medicinal plant and local biodiversity protectionat large scale. Synergies of various stakeholders at different levels were undertaken to strengthen local ecosystem conservation projects in Nagarparkar area of district Tharparkar by involving indigenous communities through in-situ Commiphora wightii proliferation, plantation and awareness raising programmes. Optimistic results were achieved from local communities' participation in various activities, plantation of 4250 Commiphora wightii(three and half months old)was carried out through vegetative cuttings at the selected natural rangeland sites in the study area.
\end{abstract}

Keywords Commiphorawightii, Tharparkar, Conservation, Biodiversity, Green Guard

\section{Background}

District Tharparkar is located $433 \mathrm{Km}$ away from Karachi, in the south-eastern part of Pakistan, and spread over 19,638 sq. Km,the only fertile desert of the world which is attributed geographically beautiful landscape, unique flora and fauna, cultural, and traditional biodiversity. For these qualities this desert is known as open air museum [25]. Arid zone ecology of Tharparkar is exclusive in its nature with distinct rangeland characteristics, and its landscape is among major ecosystems of Indus eco-regions in Pakistan which is now under environmental threat due to natural and anthropogenic reasons [27] . Pakistan is no exception from the rest of the world regarding loss of biodiversity. Deforestation, unplanned urbanization, population explosion, and unsustainable use of natural resources have exerted enormous pressure on plant biodiversity [1] . Regrettably, not much work has been carried out on conservation of endangered plant species of Pakistan [2]. Similarly, less work is under taken for the conservation of natural resources in Pakistan as well.

Nagarparakr, sub-district of Tharparkar, adjacent to the Indian border in the east-northern edge of Rann of Kutch, is exclusive terrain with flat land and hilly topography of Karoonjhar mountain range. This part of the district is rich in biodiversity including some internationally significant wild plant and animal species, this area is a wildlife sanctuary under the provincial law and part of Rann of Kutch ramsar site as well [19]. However lack of awareness, poverty, changing pattern of land use, droughts and changing climatic conditions, scan rainfall, loopholes in the government regulations have provided more and more ground to the wild plant species towards extinction. This problem is more desperate in some arid areas, particularly Nagarparkar town and surrounding villages of this area which is home to many plant species endemic to the region. Several of these serve for fuel, fibre, food, timber, medicine and local agriculture is widely rely on this floral basis. Karoonjhar hills of the Nagarparkar grow various herbs and medicinal plants; many of them are yet to be explored from scientific community, it 
attracts business sector for commercial purposes as well. Simultaneously, these plant species are highly significant to the indigenous communities from hundreds of years for their medicinal needs. Extinction of plant species in their wilderness would be an irreplaceable loss from conservation point of view, socio-economic and scientific losses have no exception too in this regard. Native plant species are integral parts of the world-wide bio-diversity, these plants play key function in our ecosystem where confronting with several risks i.e. habitat loss and degradation, introduction of alien species, pollution and diseases, over-exploitation and climate $[18 ; 14 ; 26 ; 17 ; 3 ; 4 ; 20 ; 15]$.

Most of rural population in surrounding union councils and villages of Nagarparkar is economically deprived from the basic needs of life which further lead to the poverty. These communities largely depend on local natural resources for their survival due to rain-fed agriculture. These resources are facing threats from different unsustainable human activities i.e. over-grazing, shifting cultivation, uncontrolled cropping, fuel wood, and various other activities causing loss of natural habitat[18]. Most of the local communities are rain-dependent and thus are nomadic in their life style; and keep on moving with their livestock to different areas within and out of their district which has negative implication on the flora [27]. Livestock mainly cows, goats and sheep are major livelihood source of these communities, however manifold growing number of the cattle requires more vegetation for food, resulting in serious threat to several native plant species, since equilibrium between carrying capacity of this rangeland and number of cattle is important. Driving forces responsible for these activities are both physical and socio-economic in nature including lease policy of government for agriculture land, lack of environmental awareness, low literacy rate, growing demands of these products in the market [18], and lack of ownership, political will and lack of commitment to the conservation of natural resources.

Commiphora wightii(Arnott) Bhandari(Burseraceae family) is threatened, slow growing, multi-branched with soft stem shrub (locally known as guglan or gugral) found in arid, rocky swathes of the Nagarparkar terrain(Fig. 1a). The oleo-gum mastic of $C$. wightii (locally called gugral gum), is stated in the classic Ayurvedic writings as an effective cure for bone fissures, arthritis, inflammation, obesity, cardiovascular disease, and lipid disorders[23; 24].The gum is taken out of the bark of the plant by resin tapping. A mature tapping shrub takes almost 10 years of growing period under the arid environmental conditions. Small cuts are applied by axe on the plant body during winter season to take out the gum resin(Fig. 1b). Overuse, slow growth and linked poor seed are main factors causing this plant species to be endangered [13]. Red Data list of IUCN declares gugral as Data Deficient since limited information is accessible about its conservation status [10].

Usually, indigenous people make a mixture of ass urine, garlic, asafoetida and copper sulphate by their own, using this traditional technique they dip the axe into this chemical mixture and then apply deep cuts on the whole plant body to extract optimum quantity of gum resin from guglan. This unnatural method of tapping increases the amount of resin three to four fold against normal way of tapping, later plant becomes ill and subsequently unhealthy for extracting gum for the next couple of years and finally shrub might not survive because of lethal effect of copper sulphate[11]. Death of the guglan forests is considered the main reason for unsustainable way of gum extraction, which increases gum productivity but kills the plant in short-run.

Local communities play key role in in-situ conservation of local flora and fauna as these indigenous people have local wisdom about their ecosystem. Their full involvement in programs of biodiversity conservation and managing natural resources in a sustainable way would give encouraging and reduced cost conservation and management outcomes in several parts world-wide [18].The presented study is a reflection of participatory efforts made by involving local communities and stakeholders to activate and raise awareness among local people of Tharparkar, particularly Nagarparkar about the significance and sustainable use of $C$. wightii. The main objective was to combat desertification with the participation of local stakeholders, by protecting rangelands of Nangarparkar including Karoonghar biodiversity rich fragile habitat, from unsustainable exploiting of the vegetation cover in the rangelands. A large scale $C$. wightii plantation was carried out on rangeland to conserve local ecology and secure livelihood opportunities for the poor communities.

\section{Actions}

\subsection{Orientation to Stakeholders}

In the beginning of October 2009, all the concerned stakeholders including local government officials, non-governmental organizations (NGOs), community-based organizations (CBOs), environmental journalists, politicians, social activists, civil and military officers, judiciary etc. of district Tharparkar were approached and briefed about the main activities being implemented for their understanding and collaboration to gain support in an integrated way for necessary actions required to combat desertification by protecting local ecology. Inception workshops about conservation activities were conducted in all sub-districts of Tharparkar. Visits paid to 49 villages of two union councils (UCs) 1 of Nagarparkar sub-district to on-board the local community and sensitised them for their effective participation in the conservation activities of C.wightii and protection of local biodiversity. This orientation approach proved as successful with the active participation from all relevant stakeholders and as a result, developed a consensus among different stakeholders involved which later resulted in a very conducive environment and built a momentum

1A small administrative unit 
from biodiversity conservation point of view.
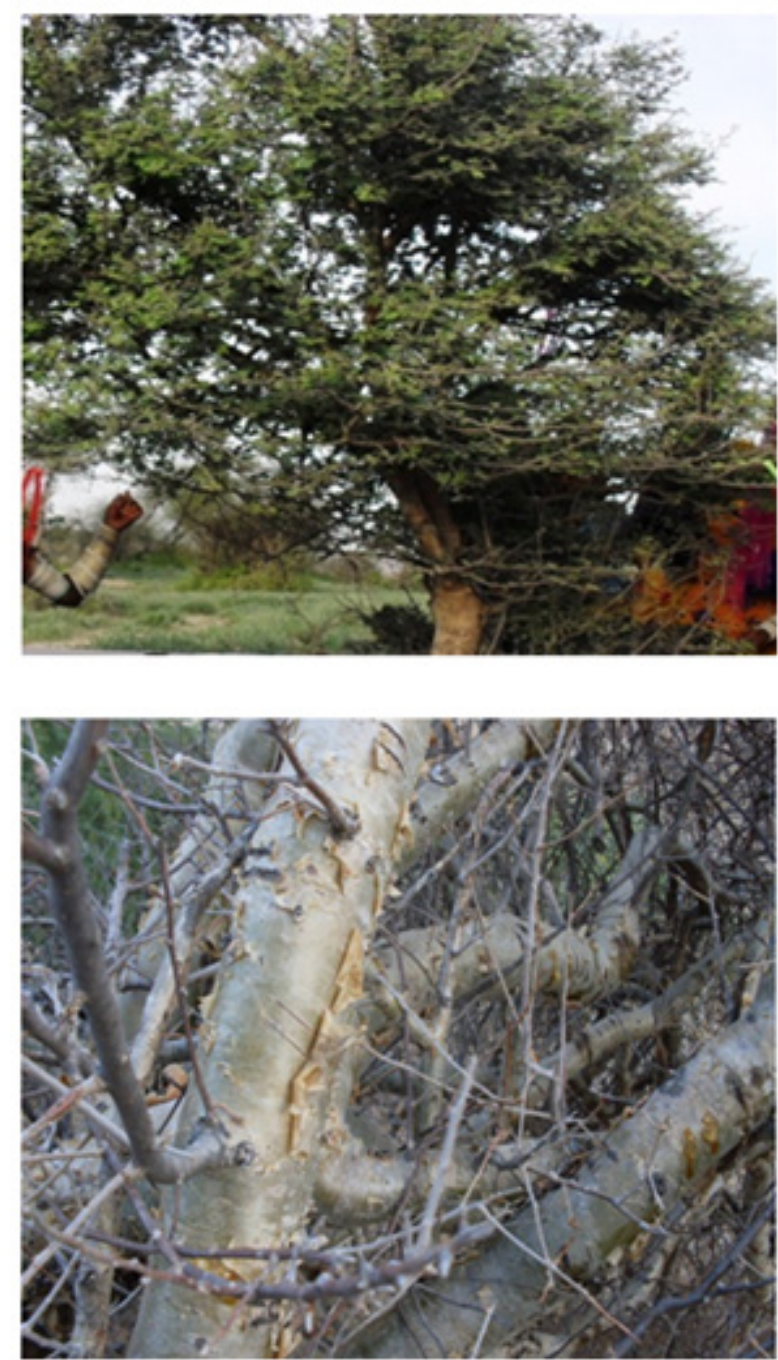

Figure 1(a). A mature Commiphora.wightiiplant in Nagarparkar, Tharparkar; (b) Resin tapping from gugral plant body

\subsection{Green Guards and Forest Vigilance Committees}

Green Guards (GGs) were a typical part of C.wightii conservation activities. During preliminary interaction with indigenous community some motivated people from the villages were selected on voluntarily basis as GGs. Their role was to mobilize other people of their community to participate in conservation practices and pass awareness to other members. Later, these GGs were given knowledge through trainings about protection of local biodiversity and C.wightii plantation procedures. In order to integrate the efforts of GGs, a Central Green Council (CGC) headed by a president and a Cooperative of Indigenous People (CIP) headed by a village focal point were formed in each UC. In the CGC, each deh2 had a deh organizer and each UC had a UC organizer, whereas CIP had village focal points. All GGs

2A smaller tier of administration unit than UC were members of both CGC and CIP. The idea was to provide community a platform where they can meet and share their ideas with each other put synergies for their role in the conservation of natural resources and ecology of their area.These GGs were given a whistle, cap and a jacket with GG logo (Fig. 3).

District and Session courts of Tharparkar district was informed about illegal practice of gum extraction from C.wightii, poaching of wildlife and deforestation. Honourable court called a high profile meeting of all government departments to stop these activities in the district and made vigilance committees at district and sub-district level to oversee biodiversity issues and take appropriate timely measures. These formal vigilance committees triggered all government departments to take attention and actions for any illegal practice jeopardizing local ecology of the district.

\subsection{Field Surveys}

To know prevailing density of C.wightii and health of the rangeland, field assessments were under taken in the study area (Fig. 2). Information about C.wightii were collected in both UCs using questionnaire surveys, community discussions, dealers of gum resin and direct field observations. Moreover, Arid Zone Research Institute (AZRI),Umerkot district range department and Pakistan Agriculture Research Council (PARC) were approached to obtain information about existence status of C.wightii. Besides feedback obtained from trained GGs, shepherds, educated and older people of the community were also taken into account to obtain local knowledge about the status of C.wightii.

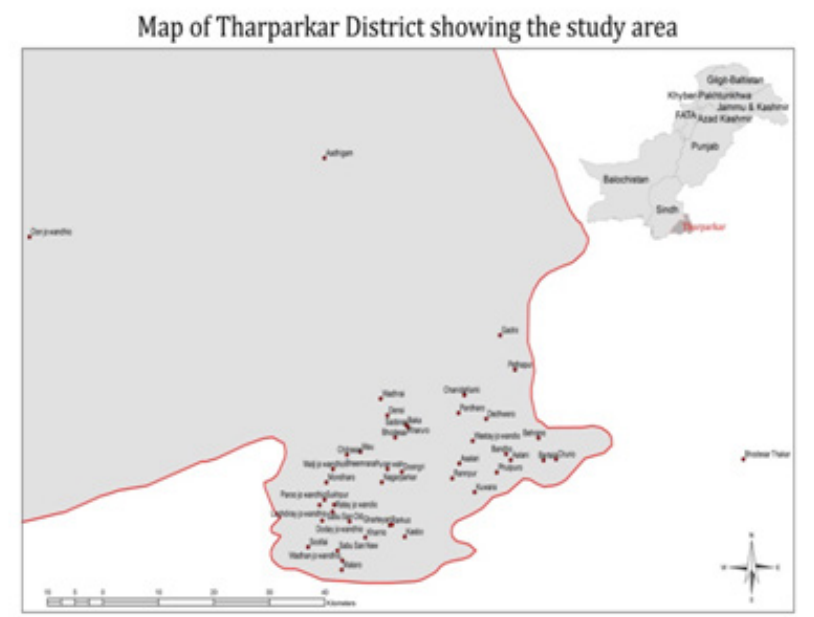

Figure 2. Map of Tharparkar district, showing the study area

\subsection{Awareness Raising Activities}

Raising awareness among local communities is significant part for biodiversity conservation that helps in developing sense of ownership amongst local people and sustainable use 
of their natural resources (Reference). In this regard, several activities were undertaken in the study area and through print and electronic media as well to spread conservation messages to the rest of masses as well. These included training of 245 GGs, rakhi bandhan event in the community (inspired from Chipko movement of India, local women tied rakhis to the trees meaning that, they considered trees as their brothers, a promise of protection),local FM radio messages, and 27 school environmental clubs for children. During these awareness sessions, local communities were given information about their dependency on natural ecology and its importance for conservation in order to continue getting benefits from local biodiversity in the long-run as their livelihood. GGs with local people of different age groups and were given knowledge for the future assessment of C.wightii and discouraging tapping of resin by applying chemical. These people further disseminated these environmental messages to their friends, relatives and other spheres of influence (Fig. 3).
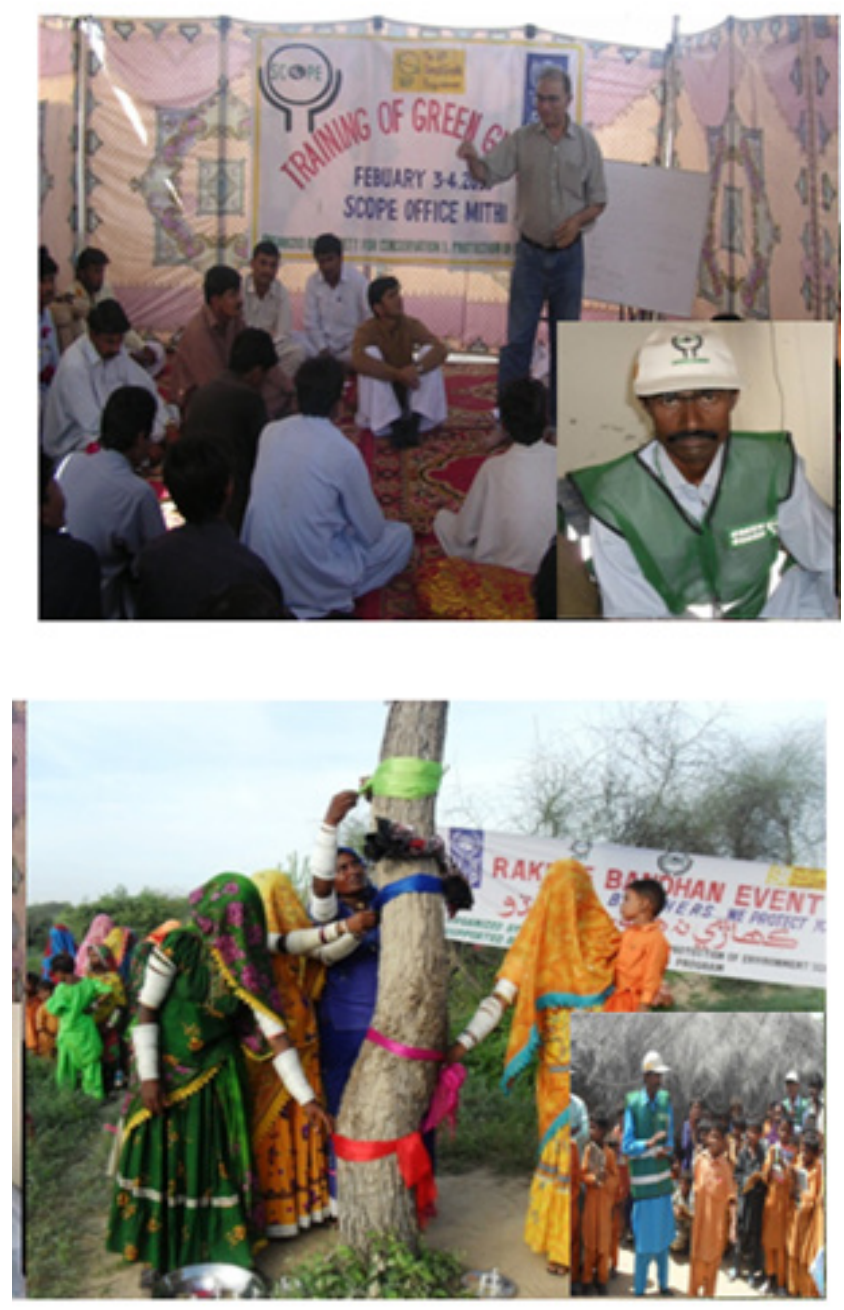

Figure 3. Awareness raising activities among Green Guards and local community members

\subsection{Vegetative Propagation of $C$.wightii through Stem Cutting}

Different suitable rangeland sites were identified in the study area with the support of local community and rangeland department forlarge scale propagation of C.wightii. In this regards, a guglan nursery was developed with the support of GGs in the beginning of May 2010. Cuttings were taken from healthy and disease free branches of the plant. The basal parts of the cuttings were immersed in newly made $1500 \mathrm{mg} / \mathrm{l}$ aqueous solution of Indole-3-butyric acid solution for 5 seconds [12]. Under green-shaded $(50 \%$ with green plastic mesh) nursery, these cuttings were shifted to plastic bags of $4 \mathrm{~cm}$ deep filled with manure and soil by ratio of 3:1. Nursery was covered with the plastic mesh to safeguard saplings from exposure of direct sunlight. Favourable growth time for C.wightii is rainy monsoon season; 4250 plantlets, 3.5 months old (each with an approx. $30.5 \mathrm{~cm}$ height) were then planted to the identified rangeland sites during (July-August 2010) by involving GGs and local people.

\section{Consequences}

\subsection{Orientation to Stakeholders}

All the stakeholders were kept informed from the inception about the conservation activities being carried out in the area, this network brought very good results, such as it drew attention of local, national[15a;16b] and international media $[5 ; 6 ; 22 ; 7 ; 8 ; 21 ; 9]$ to highlight this issue which received governments' consideration to execute required measures for the conservation of C.wightii and other biodiversity. District judiciary took positive steps to halt illegal deforestation and poaching of wildlife in the district. Ombudsman from government department paid visits to Nagaraparkar area to investigate illegal tapping of C.wightii and took deterring actions. Importantly, advisor to chief minister of Sindh province notice the problem paid visit to the area and forwarded this matter to the government for consideration. Moreover, community exposure visit from WWF-Pakistan spread conservation message to their area of working.

\subsection{Green Guards and Forest Vigilance Committees}

GGs participated proactively in all the conservation supportive activities in the Nagarparkar area to protect C.wightii and other important local wildlife as well. GGs used their local knowledge and traditional way of conservation, such as they took community members in confidence and made check points at different locations to monitor illegal hunting and cutting of trees, they used given whistles to alert one another, they divided study area into different sectors by mutual agreement and did patrolling wearing cap and jacket with GG logo, which made them distinguished among other community members. During various occasion, network of GGs saved migratory birds and local wildlife such as Demoiselle Crane (Anthropoidesvirgo), Houbara Bustard (Chlamydotisundulata), Blue bull 
(Boselaphustrago camelusare), Indian Peafowl (Pavocristatus) and Chinkara from poaching and timely informed concerned government departments. Later, it was noticed that other young people from different villages wanted to be GG, which showed level of inspiration. Formation of vigilance committees ordered by District and Session court influenced conservation efforts positively overall the district, government departments such as wildlife, forest, revenue, police, rangers, local persons from NGOs and media were members of these committees. These committees conducted regular meetings and discussed and identified threats in the district, in some cases legal actions were also taken by the local police. Support from district government, local community and efforts of GGs checked unsustainable tapping significantly during the year 2010.In addition, efforts from GGs proved as agents for community managed rangelands, indigenous communities realized the importance of their nexus with their natural rangelands, they considered rotational grazing, planting and protecting existing vegetation to maintain healthy rangelands for nature and themselves.

\subsection{Field Surveys Results}

Survey results revealed, UC Pethapur and Nagarparkar of sub-district Nagarparkarare 'hotspots' for C. wightii, however it is also found in UCs including Muhrano and Manjthi of sub-district Mithi, Jhermryo and Diplo of sub-district Diplo, and UC Kanteyo of sub-district Chacharo in district Tharparkar and some parts of adjacent district Badin as well. It was concluded that $C$. wightii is being wiped out intensively. During discussions with GGs and local community members of older age, told that few decades ago they couldn't walk through the $C$. wightii forests while grazing their goats on the Karoonjhar hills. It was obvious; drastically reduction in the population of $C$. wightii is the result of deploying poor labourers by some influential people to extract gum resin using unsustainable way for commercial purposes. Workers were given small size axes, and ethephon (2-chloroethyl phosphoric acid, a synthetic chemical releases ethylene) to extract higher amount of gum. This short-term method of tapping is lucrative for enterprise oriented reasons, but eventually plant dies in medium-term.

\subsection{Awareness Raising Activities}

Overall impacts of training to GGs, orientation workshops to stakeholders, local FM radio programmes, rakhi bandhan event, and awareness sessions among local communities remained optimistic. All these activities raised awareness level of indigenous people considerably about conservation of C.wightii and created a sense of ownership about sustainable use of natural resources and their protection. GGs reinforced centuries old traditional panchayat (village council) system in their villages which is now fading away due to changing pattern of rural society. This panchayat system is like a unity system of villagers; they discuss and try to solve their problems. Loss of local biodiversity is equal to loss of their livelihood means; GGs held regular meetings with their villagers by involving children, women and man of all age groups and conveyed conservations messages. Villagers were observed planting C.wightii plants around their houses and some schools as fencing walls. Moreover, locals supported in stopping poaching of wildlife incidents around Karoonjhar hilly areas and actively participated in large scale C.wightii plantation activities in order to restore this plant species in the natural habitat (Figure 4).
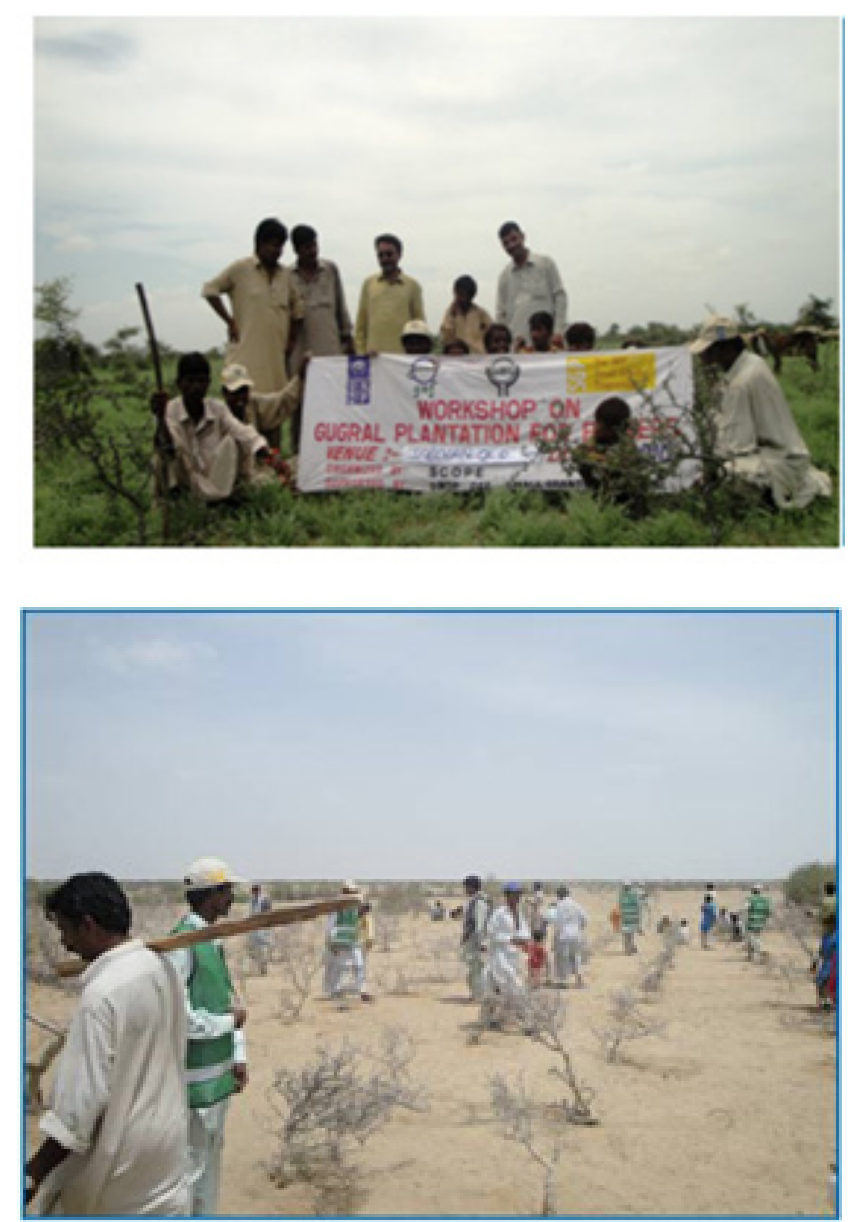

Figure 4. C.wightii plantation activities by GGs and local villagers of Karoonjhar hilly areas

\subsection{Vegetative Propagation of $C$.wightii and Relocation}

During first phase, stem-cuttings were placed in the soil and manure filled plastic bags, nursery observations showed that within a time period of 20 days stem-cuttings started sprouting under favourable climatic conditions. Increasing rate of budding and growth was noticed in the plant saplings when stem cutting acquired diameter from 0.6 to $0.8 \mathrm{~mm}$. After, 20 to 30 days roots growth was observed in the stem-cuttings, same results were achieved by [18]. Later, GGs and local community were involved in shifting these plantlets to the identified plantation sites around Karoonjhar hills (Fig 4). 


\section{Conclusions}

Community-based approach is significant as well as successful for local biodiversity conservation programmes as discussed in this paper. A participatory effort from all stakeholders by understanding local environmental and socio-economic dynamics of the area and integrating it in conservation aspects is integral for the success. Local wisdom is important to be cohesive with scientific knowledge to produce innovative natural resources conservation approaches and embed them in various tiers of planning. Poor rural communities are largely depended on their local natural resources for livelihood; therefore health of local ecosystem must not be comprised by short-term benefits and loopholes in the governance systems must be overcome at different levels of management to protect natural resource base.

\section{Acknowledgements}

This study has been made possible by affiliation of corresponding author with Society for Conservation and Protection of Environment (SCOPE)-Pakistan in a UNDP-GEF funded project "Combating Desertification by Participatory Action in Tharparkar, Sindh, Pakistan" implemented by SCOPE.Authors are thankful to Mr.TanveerArif CEO, and Mahjabeen Khan (Programme Manager) SCOPE for their kind support.

\section{REFERENCES}

[1] Abbas, Haider, M. Qaiser, and J. Alam. 2010. "Conservation Status of Cadaba Heterotricha Stocks (capparaceae): An Endangered Species in Pakistan, Pakistan Journal of Botany, Vol.42,NO.1, 35-46.

[2] Alam, J., and S.L. Ali. 2009. Conservation Status of Astraglus Gilgitensis Ali (Fabaceae): a Critically Endangered Species in Gilgit District, Pakistan, Phyton (Horn, Austria),Vol. 48 ,NO.2, 211-223.

[3] Alonso, A., F. Dallmeier, E. Granek, and P. Raven. Biodiversity: Connecting with the Tapestry of Life. Smithsonian Institution/Monitoring and Assessment of Biodiversity Program and President's Committee of Advisors on Science and Technology. Washington, DC. 2001.

[4] Barbosa, O., and P.A. Marquet. 2002. Effects of Forest Fragmentation on the Beetle Assemblage at the Relict Forest of Fray Jorge, Chile, Oecologia ,Vol.,No.132, 296-306.

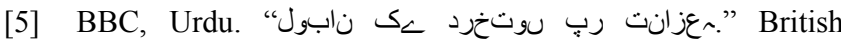
Broadcasting Corporation Urdu Service,on line avaialble from

http://www.bbc.co.uk/urdu/pakistan/2010/01/100129_loban_ thar.shtml.

[6] BBC, Urdu. "ظف." British
Broadcasting Corporation Urdu Service, on line avaialble from http://www.bbc.co.uk/urdu/pakistan/2011/08/110815_peacoc k _guards_zs.shtml.

[7] Dawn. Thari Women Tie Rakhis to Trees, on line avaialble from http://archives.dawn.com/archives/76144.

[8] [8] Dawn. Gum Trees Are Ruthlessly Being Destroyed in Thar, on line avaialble from http://dawn.com/2011/01/07/gu $\mathrm{m}$-trees-are-ruthlessly-being-destroyed-in-thar/.

[9] Dawn. Environment: The Vanishing Forests, on line avaialble from http://dawn.com/2012/06/10/environment-the -vanishing-forests/.

[10] IUCN. The IUCN Red Data List of Threatened Species. http://www.iucnredlist.org/details/31231/0.

[11] Kshetrapal, S, and R Sharma. Tudies on the Effect Various Plant Extracts on the Sprouting Behaviour of Cuttings of Commiphora Wightii (Arnott) Bhandari and C. Agallocha Engl, Journal of the Indian Botanical Society,Vol. 72, 73-75, 1993.

[12] Kumar, D, R Chandra, and O.R Aishwath. Biomass Partitioning and Cutting Success as Influenced by Indole Butyric Acid in Softwood Cuttings of Indian Bdellium [Commiphora Wightii (Arnot.) Bhand.]. Biomass Partitioning and Cutting Success as Influenced by Indole Butyric Acid in Softwood Cuttings of Indian Bdellium [Commiphora Wightii (Arnot.) Bhand, 49-52. 2006.

[13] Kumar, S, S.S Suri, K.C Sonie, and K.G Ramawat. Establishment of Embryonic Cultures and Somatic Embryogenesis in Callus Culture of guggul-Commiphora Wightii (Arnott.) Bhandari. Indian Journal of Experimental Biology ,No.4, 69-77, 2003.

[14] McNeelyJ.A., C. Leveque M. Gadgil, C. Redford, and K.Padoch. Human Influences on Biodiversity. In Global Biodiversity Assessment, Cambridge: Cambridge University Press and United Nations Environment Programme,London, 1995.

[15] Pakistan, Times(a). 2011. SCOPE, Sharmila Farooqui Call for Conserving Gugral Tree, Available on line http://www.pak-times.com/2011/07/21/scope-sharmila-faroo qui-call-for-conserving-endangered-gugral/.

[16] Pakistan, Times(b). 2011. "Livestock Rearing in Tharparkar at Stake as 'rangelands' Turn Farmlands", Available on line http://www.pak-times.com/2011/07/23/livestock-rearing-in-t harparkar-at-stake-as-rangelands-turns-into-farmlands/.

[17] Sala, O.E., F.S. Chapin, J.J. Armesto, E. Berlow, J. Bloomfield, R. Dirzo, E. Huber-Sanwald . Global Biodiversity Scenarios for the Year 2100, Science,Vol. 287, No.5459,1770-74, 2000.

[18] Soni, Vineet .Conservation of Commiphora Wightii, an Endangered Medicinal Shrub, Through Propagation and Planting, and Education Awareness Programs in the Aravali Hills Of': 27-31, . 2010.

[19] Sindh Wildlife, Department.2013. "Wildlife Protected Areas in Sindh,Available on line http://www.sindhwildlife.com.pk/protectedareas/protected_p age.htm.

[20] Sudhersan, C., M. Abo El-Nil, and J. Hussain. "Tissue Culture Technology for the Conservation and Propagation of Certain Native Plants." Journal of Arid Environment,Vol. 
54,133-147, 2003.

[21] The Nation, International.. Sharmila Annoyed over Deforestation, Available on line http://www.nation.com.pk/pakistan-news-newspaper-daily-e nglish-online/karachi/22-Dec-2009/Sharmila-annoyed-over-deforestation.

[22] The News, International. 2011. "Concern Voiced over Increasing Peacock Deaths in Thar", February 13. http://www.thenews.com.pk/TodaysPrintDetail.aspx?ID=30 $852 \&$ Cat $=4 \& \mathrm{dt}=2 / 13 / 2011$.

[23] Urizar, N.L, and D.D Moore. Guggulipid: A Natural Cholesterol-Lowering Agent. Annual Review of Nutrition,Vol. 23,303-313, 2003.
[24] Wang, X, J Greilberger, G Ledinski, G Kager, B BPaigen, and $G$ Jurgens. The Hypolipidemic Natural Product Commiphora Mukul and Its Component Guggulsterone Inhibit Oxidative Modification of LDL. Atherosclerosis, Vol. 172, 239-246, 2004.

[25] Wikipedia. Tharparkar,Avilable on linehttp://en.wikipedia.or g/wiki/Tharparkar [Accessed 6 March 2013].

[26] Wilcove, D.S., D. Rothstein, J. Dubow, A. Phillips, and E. Losos. Quantifying Threats to Imperiled Species in the United States, Bioscience 48: 607-615, 1998.

[27] WWF-Pakistan.Major Ecosystems, Avilable on line http://www.wwfpak.org/foreverindus/ie_ecosystem.php [Accessed 6 March 2013]. 